Roche, Pfizer, Abbvie, Consultant for: Novartis, Roche, Speakers bureau: MSD, Roche, Pfizer, Abbvie,Celltrion, Novartis, Pamir Atagündüz: None declared, Belkıs Nihan Coşkun: None declared, Burcu Yağız: None declared, Süleyman Serdar Koca: None declared, Muhammet Çınar: None declared, Aşkın Ateş: None declared, Servet Akar Grant/research support from: MSD, Abbvie, Roche, UCB, Novartis, Pfizer, Amgen, Consultant for: MSD, Abbvie, Roche, UCB, Novartis, Pfizer, Amgen, Speakers bureau: Pfizer, Onay Gercik: None declared, Duygu Ersözlü: None declared, Veli Yazısız: None declared, Gezmiş Kimyon: None declared, Müge Aydın: None declared, Rıdvan Mercan: None declared, Burak Öz: None declared, Nazife Sule Yasar Bilge: None declared, Zeynel Abidin Akar: None declared, Omer Karadag: None declared, Ayse Bahar Kelesoglu Dincer: None declared, Sedat Yilmaz: None declared, Ufuk Illgen: None declared, Yavuz Pehlivan: None declared, Ender Terzioğlu: None declared, Levent Kılıç: None declared, Şükran Erten: None declared, Ali İhsan Ertenli: None declared

DOI: 10.1136/annrheumdis-2019-eular.5285

\section{FRI0396 CHARACTERIZATION OF PATIENTS WITH INFLAMMATORY BOWEL DISEASE IN THE ANKYLOSING SPONDYLITIS COHORT PRIOR AND DURING ADALIMUMAB TREATMENT: DATA FROM A LARGE GERMAN NON-INTERVENTIONAL STUDY}

Michaela Köhm $^{1,2}$, Marc Schmalzing ${ }^{3}$, Eva Christina Schwaneck ${ }^{3}$, Holger Gnann ${ }^{4}$, Hans-Peter Tony ${ }^{3}$, Gerd Greger ${ }^{5}$, Annika Boas ${ }^{5}$, Harald Burkhardt ${ }^{1,2,6}$,

Frank Behrens ${ }^{1,2,6}$. ${ }^{1}$ Rheumatology Department, University Hospital GoetheUniversity, Frankfurt, Germany, ${ }^{2}$ Fraunhofer IME Branch for Translational Medicine and Pharmacology, Frankfurt, Germany; ${ }^{3}$ Department of Rheumatology and Immunology, University Hospital, Würzburg, Germany; ${ }^{4}$ GKM, München, Germany, ${ }^{5}$ AbbVie, Wiesbaden, Germany; ${ }^{6}$ Centre of Innovative Diagnostics and Therapeutics Rheumatology/Immunology at Goethe-University, Frankfurt, Germany

Background: Spondylarthritidies (SpA) are characterized by different disease manifestations such as arthritis, enthesitis, dactylitis and associated to concomitant diseases like Inflammatory bowel diseases (IBD) including ulcerative colitis (UC) and crohn's disease (CD). IBD might have a specific role to $\mathrm{SpA}$ due to common pathophysiological pathways. Characteristics of the rheumatic disease and response to treatment may differ within the phenotypic manifestation and with and without associated diseases. Adalimumab (ADA) is a monoclonal antibody inhibiting TNF alpha which has demonstrated efficacy in both, nraxSpA and ankylosing spondylitis (AS) as well as for UC and CD.

Objectives: To evaluate patient baseline characteristics prior to and treatment response on different disease manifestations in a cohort of AS patients with IBD compared to an AS without IBD during ADA treatment. Methods: Data from a large German multicenter prospective observational non-interventional study $(n=3.756)$ of patients with active AS who initiated ADA therapy during routine clinical care were analyzed with focus on specific patient groups: (1) patients with AS and IBD at baseline $(n=166)$ and (2) patients with AS without IBD at baseline $(n=3.590)$. Patient characteristics and data of efficacy on different disease manifestations and prevalence of concomitant IBD over 24 months were analyzed.

Results: Of 3.756 patients in the main analysis set, $166(4.4 \%)$ were identified to suffer from concomitant IBD at baseline. Baseline characteristics showed differences in gender distribution, proportion of patients with enthesitis, psoriasis and uveitis showing a higher proportion of each for the IBD group (Table). After 24 months of ADA treatment, both groups had similar decreases for BASDAI, BASMI, BASFI and dactylitis improvement. The IBD group had a fast decrease in BASDAI at M6 to its maximum improvement (delta of 1.9) which was kept stable until M24. For clearance of enthesitis, ADA had its largest therapeutic effect at M6 in the IBD group (clearance in $15.3 \%$ of the patients) while the AS without IBD group had the largest decrease of $10.2 \%$ at month 24 . Resolving of uveitis with ADA therapy was more often seen in the IBD group compared to the AS without IBD (delta of $6 \%$ at M12 compared to delta of $2.6 \%$ at $\mathrm{M} 12$, respectively). The prevalence of IBD in AS in patients treated with ADA changed from $4.4 \%$ at baseline to $1.9 \%$ at M24. Conclusion: Within the cohort of AS, patients' characteristics of manifestations are associated to different treatment responses: Patients identified to have IBD at baseline respond better for resolving of enthesitis and show a faster response in BASDAl compared to the group without IBD. Overall a significant reduction in the prevalence of clinically relevant IBD was seen earliest at month 3 after ADA initiation.
Table. Baseline characteristics of patients with IBD within the documented AS cohort treated with ADA

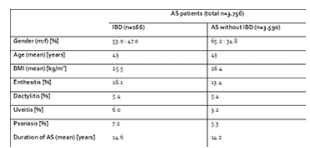

Acknowledgement: This study was sponsored by AbbVie Deutschland $\mathrm{GmbH}$ \& Co KG. AbbVie contributed to the study design, data analysis, and in the writing, revision, and approval of the abstract. Medical writing services were provided by CIRI, Frankfurt am Main, Germany, under contract with AbbVie for medical writing services.

Disclosure of Interests: Michaela Köhm Grant/research support from: BMS, Pfizer, Janssen, Consultant for: BMS, Pfizer, Janssen; AbbVie, Speakers bureau: BMS, Pfizer, Janssen, AbbVie, Marc Schmalzing Grant research support from: Pfizer, Chugai, MSD, Janssen-Cilag, BMS, Celgene, UCB, Consultant for: Abbvie, Chugai, Genzyme, Hexal/Sandoz, MSD, Novartis, Roche, Sanofi Pasteur, Speakers bureau: Actelion, Baxalta/Shire, BMS, Celgene, Chugai, Janssen-Cilag, MSD, Novartis, Pfizer, Roche, UCB, Eva Christina Schwaneck: None declared, Holger Gnann: None declared, Hans-Peter Tony Consultant for: Eli Lilly and Company, Speakers bureau: Eli Lilly and Company, Gerd Greger : None declared Annika Boas Shareholder of: AbbVie, Harald Burkhardt Grant/research support from: BMS, Pfizer, Janssen, Consultant for: AbbVie, BMS, Pfizer, Janssen, Roche, Chugai, Speakers bureau: AbbVie, BMS, Pfizer, Jans sen, Roche, Chugai, Frank Behrens Grant/research support from: AbbVie, Pfizer, Roche, Chugai, Prophylix, Bioline, Novartis, Consultant for: AbbVie, Pfizer, Roche, Chugai, UCB, Bristol-Myers Squibb, Celgene, MSD, Novartis, Biotest, Janssen, Genzyme, Eli Lilly, Speakers bureau: Ad board: AbbVie, Pfizer, Roche, Chugai, UCB, Bristol-Myers Squibb, Celgene, Novartis, Biotest, Janssen, Genzyme, Eli Lilly

DOI: 10.1136/annrheumdis-2019-eular.5464

\section{FRI0397 EFFICACY AND SAFETY OUTCOMES IN PATIENTS WITH AXIAL SPONDYLOARTHRITIS TREATED WITH CERTOLIZUMAB PEGOL: RESULTS FROM THE 48- WEEK RUN-IN PART OF C-OPTIMISE}

$\underline{\text { Robert B.M. Landewé }}^{1}$, Désirée van der Heijde ${ }^{2}$, Maxime Dougados ${ }^{3}$,

Xenofon Baraliakos ${ }^{4}$, Filip van den Bosch ${ }^{5}$, Karl Gaffney ${ }^{6}$, Natasha de Peyrecave ${ }^{7}$, Lars Bauer ${ }^{8}$, Bengt Hoepken ${ }^{8}$, Karen Thomas ${ }^{8}$, Lianne S. Gensler ${ }^{9}$. ${ }^{1}$ Amsterdam Rheumatology and Clinical Immunology Center, Amsterdam, and Zuyderland MC, Heerlen, Netherlands; ${ }^{2}$ Department of Rheumatology, Leiden University Medical Center, Leiden, Netherlands; ${ }^{3}$ Rheumatology Department, Paris-Descartes University and Cochin Hospital, Paris, France; ${ }^{4}$ Ruhr-University Bochum, Herne, Germany, ${ }^{5}$ Department of Internal Medicine, Ghent University Hospital, Ghent, Belgium; ${ }^{6}$ Rheumatology Department, Norfolk and Norwich University Hospital NHS Foundation Trust, Norwich, United Kingdom; ' ${ }^{7}$ CB Pharma, Brussels, Belgium; ${ }^{8}$ UCB Pharma, Monheim, Germany; ${ }^{9}$ University of California, San Francisco,

CA, United States of America

Background: C-OPTIMISE is the first trial to evaluate whether certolizumab pegol (CZP) can be reduced/discontinued in patients with radiographic(r)-axSpA/ankylosing spondylitis (AS) and non-radiographic(nr)-axSpA achieving sustained remission after 48 weeks' (wks') treatment.

Objectives: Here, we report interim efficacy and safety data for both subpopulations from the ongoing trial.

Methods: Up to Wk48, C-OPTIMISE (NCT02505542) was open-label (Part A), followed by 48-wk parallel-group, double-blind, placebo-controlled treatment (full dose and half dose) to Wk96 (Part B). Patients with adult-onset axSpA of $<5$ years' duration, fulfilling Assessment of SpondyloArthritis international Society (ASAS) classification criteria, were recruited. Part A: patients received CZP $400 \mathrm{mg}$ at $\mathrm{Wks} 0 / 2 / 4$, then 200mg every 2 weeks [Q2W]); patients achieving sustained remission (Ankylosing Spondylitis Disease Activity Score $[$ ASDAS] $<1.3$ at Wk32 and $<2.1$ at Wk36 [or vice versa], and $<1.3$ at Wk48) were eligible for Part B (secondary outcome). Primary outcome (not reported): percentage of patients in Part B not experiencing a flare. Missing values were imputed using non-responder imputation (NRI) and last observation carried forward (LOCF).

Results: Part A: Of 736 patients (Table A), 43.9\% achieved sustained remission ( $r$-axSpA/AS: 42.8\%; nr-axSpA: 45.3\%; NRI). At baseline, $98.5 \%$ patients had high/very high disease activity (ASDAS $\geq 2.1$ ); at Wk48, 